\title{
Article \\ Surface Property Modification of Collagen, Hyaluronic Acid, and Chitosan Films with the Neodymium Laser
}

\author{
Sylwia Grabska-Zielińska ${ }^{1, * \mathbb{D}}$ and Alina Sionkowska ${ }^{2}$ (D) \\ 1 Department of Physical Chemistry and Physicochemistry of Polymers, Faculty of Chemistry, Nicolaus \\ Copernicus University in Toruń, 7 Gagarin Street, 87-100 Toruń, Poland \\ 2 Department of Chemistry of Biomaterials and Cosmetics, Faculty of Chemistry, Nicolaus Copernicus \\ University in Toruń, 7 Gagarin Street, 87-100 Toruń, Poland; as@chem.umk.pl \\ * Correspondence: sylwia.gz@umk.pl
}

check for updates

Citation: Grabska-Zielińska, S.; Sionkowska, A. Surface Property Modification of Collagen, Hyaluronic Acid, and Chitosan Films with the Neodymium Laser. Polysaccharides 2022, 3, 178-187. https://doi.org/ $10.3390 /$ polysaccharides 3010008

Academic Editor: Azizur Rahman

Received: 15 November 2020

Accepted: 10 January 2022

Published: 19 January 2022

Publisher's Note: MDPI stays neutral with regard to jurisdictional claims in published maps and institutional affiliations.

Copyright: (c) 2022 by the authors. Licensee MDPI, Basel, Switzerland. This article is an open access article distributed under the terms and conditions of the Creative Commons Attribution (CC BY) license (https:// creativecommons.org/licenses/by/ $4.0 /)$.

\begin{abstract}
In this paper, surfaces of thin films prepared from blends of collagen, hyaluronic acid, and chitosan and modified by neodymium laser radiation were researched. To evaluate the laser beam effect on the surface structure, scanning electron microscopy (SEM) imaging and infrared spectroscopy (FTIR-ATR) were employed. The results demonstrated that during laser treatment the specimens lost water due to the evaporation process. SEM images revealed some changes in the biopolymer films structure. After laser treatment, the micro-foam formation was observed on the biopolymeric films. The micro-foaming in films based on ternary blends was more extensive than in those made of a single biopolymer. The results of this study indicate that collagen, hyaluronic acid, and chitosan materials can be modified with laser treatment. Such treatment can be used for material modification for potential biomedical purposes.
\end{abstract}

Keywords: hyaluronic acid; chitosan; collagen; surface properties; laser; surface modification

\section{Introduction}

Surface properties of new materials are of significant importance for several reasons [1]. The surface also plays a pivotal role in biomedical applications of new materials prepared with the use of biopolymers. The surface can be modified in a number of ways, namely, by physico-chemical, mechanical, and biological methods. Laser treatment of biopolymer materials is one of the physico-chemical methods of surface treatment [2]. Therefore, ultrafast lasers have been commonly used in biomedical sciences due to their ability to produce micro/nanostructures that improve the biomaterial biocompatibility. Surface topography is responsible for cell adhesion, migration, multiplication, and differentiation. In general, laser material treatment and processing may include welding, drilling, cutting, surface hardening, cladding, alloying, laser-assisted forming (bending), rapid prototyping, ablation, and shot peening. During material processing with the use of a laser, the laser light strikes the superficies of the film. A part of the beam energy is reflected from the surface material, while the residual of beam energy is transferred into it, causing a high reflectivity to the laser radiation that characterizes the majority of the materials. Conversion of the absorbed energy to heat leads to several process occurrences in the materials [3,4]. Lasers are used to design the surfaces of different types of materials and can manipulate roughness and wetting characteristics [2,3]. Applications for laser-structured surfaces are emerging in different types of areas, including biomedical field, water harvesting, spectroscopic analysis, antibacterial and antifungal, and oil/water separation, etc., which have been observed recently [2,5]. The effects of several lasers on the surface properties of biopolymer films have already been studied [6,7]. Structured surfaces of several biopolymeric materials allow the application of commonly used biopolymers in an extensive range of specialized fields.

It has been demonstrated that laser energy can lead to the surface foaming of silk fibroin, chitosan, collagen, and other biopolymer films [8,9]. However, to the best of our 
knowledge, the effect of laser radiation on the surface of hyaluronic acid films has not been studied yet. Moreover, nowadays, there is a growing interest in newly designed materials based on the mixtures of two or more polymers [10]. The effect of laser radiation on several biopolymer films was studied, but the laser modification of binary and ternary biopolymer blends has not been researched yet. In this work, films made of hyaluronic acid, collagen/hyaluronic acid, and collagen/hyaluronic acid with a 30\% addition of chitosan were treated with the Nd:YAG laser beam.

Hyaluronic acid (HA) is a chemical compound, which belongs to the polysaccharides group. It is an anionic, nonsulfated glycosaminoglycan. It can also be called a hyaluronan $[11,12]$. HA is distributed widely throughout epithelial, connective, and neural tissues $[13,14]$. It is an endogenous component of human skin [15]. Additionally, it is naturally occurring in the extracellular matrix of human tissues [15]. Thanks to its strong waterbinding capacity and the possibility for fibroblast stimulation, hyaluronic acid is highly recommend for the improvement of skin elasticity, moisture, and skin wrinkles [15-17].

Collagen (Coll) is the main structural protein in the extracellular matrix of connective tissues in the body. Thus, it is the most widely occurring protein in mammals. Collagen mostly occurs in fibrous tissues, such as ligaments, tendons, and skin [18].

Chitosan (CTS) is a linear polysaccharide [19]. Chitosan can be found by treating chitin shells of shrimps and other crustaceans with alkaline substances (e.g., sodium hydroxide). Chitosan is frequently used in biomedical applications [20,21].

The interactions between hyaluronic acid, collagen, and chitosan in mixtures and materials based on hyaluronic acid/collagen/chitosan blends have been studied within the last few years [22-24]. It was found that the interactions between collagen and chitosan in a solution led to the miscibility of these biopolymers. Partial miscibility was also observed for ternary blends made of collagen, chitosan, and hyaluronic acid in a solution [23,24].

The purpose of this work was to investigate the impact of laser radiation on the structure of biopolymeric films based on hyaluronic acid, collagen/hyaluronic acid, and collagen/hyaluronic acid, with the addition of chitosan. The influence of UV irradiation on the properties of such films has been studied previously [25]. However, to the best of our knowledge, the influence of laser light on the surface properties of hyaluronic acid-based films has not been studied yet.

\section{Materials and Methods}

\subsection{Reagents}

Hyaluronic acid (HA) $\left(\mathrm{Mv}=1.8 \times 10^{6} \mathrm{~g} / \mathrm{mol}\right)$ and chitosan (CTS) (degree of deacetylation DD $=78 \% \mathrm{Mv}=1.4 \times 10^{6} \mathrm{~g} / \mathrm{mol}$ ) were supplied by Sigma Aldrich (Poznań, Poland). Collagen (Coll) was prepared in our laboratory from rat-tail tendons, according to the procedure [26]. The rat-tail tendons were excised and washed in distilled water. Next, they were dissolved in acetic acid solution $(0.1 \mathrm{M})$ for three days (fridge, $4^{\circ} \mathrm{C}$ ). The undissolved parts of the tendons were removed by centrifugation (10 $\mathrm{min}, 10,000 \mathrm{rpm}$ ). The obtained collagen solution was frozen (freezer, $\left.-18^{\circ} \mathrm{C}\right)$ and lyophilized $\left(-55^{\circ} \mathrm{C}, 5 \mathrm{~Pa}, 48 \mathrm{~h}\right.$, ALPHA 1-2 LD plus, CHRIST, Osterode am Harz, Germany) [26].

\subsection{Fabrication of Films}

Collagen and chitosan were dissolved in acetic acid solution $(0.1 \mathrm{M})$. Hyaluronic acid was dissolved in hydrochloric acid solution $(0.1 \mathrm{M})$. The percentage concentration of each polymer was $1 \%$. Biopolymers were blended together in suitable ratios and mixed with a magnetic stirrer (2-component mixture for $2 \mathrm{~h}, 3$-component mixture for $3 \mathrm{~h}$ ). The films were prepared by solvent evaporation (room temperature and humidity).

For laser treatment, the following films were prepared: (1) films made of hyaluronic acid; (2) films made of a mixture of collagen and hyaluronic acid (50/50 wt ratio); and (3) films made of a mixture of collagen and hyaluronic acid (50/50) with 30\% chitosan addition. 


\subsection{Laser Treatment}

Thin films were submitted to the fractional pulse neodymium laser radiation treatment (Nd:YAG (neodymium-doped yttrium aluminum garnet); $\mathrm{Nd}: \mathrm{Y}_{3} \mathrm{Al}_{5} \mathrm{O}_{12}$ ). In this study, the Nd:YAG laser generated $355 \mathrm{~nm}$ wavelength. The polymeric films were modified at a constant temperature and humidity. The films were radiated with a 10 -fold and 20 -fold pulse. The energy of the pulse was $100 \mathrm{~mJ}$. The scheme of the sample preparation and laser treatment is shown in Figure 1.

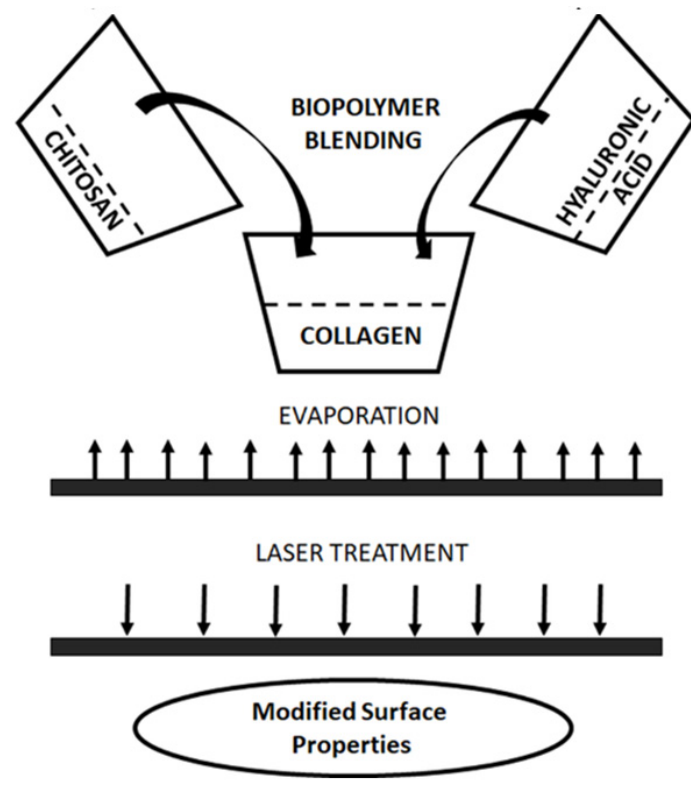

Figure 1. Preparation of biopolymer blend based on collagen, chitosan, and hyaluronic acid and laser treatment of biopolymer film.

\subsection{The Characterization of Biopolymeric Films}

The structures of the laser-treated samples were studied by FTIR-ATR spectroscopy and scanning electron microscopy (SEM) imaging.

Attenuated total reflection infrared spectroscopy was used to prepared the FTIR spectra. A Nicolet iS10 equipped with an ATR device with a diamond crystal was used as the instrument for recording each kind of sample. All of the spectra were recorded by the absorption mode at $4 \mathrm{~cm}^{-1}$ intervals and 64-times scanning. The absorption values were observed in the range of $400-4000 \mathrm{~cm}^{-1}$. The IR spectra were recorded before and after laser treatment.

The morphology of the prepared films was characterized by scanning electron microscopy (SEM) using Quanta 3D FEG. The SEM images were recorded for the surface of films before and after laser treatment.

The roughness of the films was studied by atomic force microscopy and published earlier in our previous paper [25]. The roughness parameters of the laser-treated films was studied by atomic force microscopy using the Veeco SPM (digital instrument) microscope and calculated for the scanned area $(5 \mu \mathrm{m} \times 5 \mu \mathrm{m})$ using Nanoscope software. The AFM calculations for laser-treated films were obtained for different sample places and the most typical results were presented in this paper.

The mechanical properties and contact angle measurements for native films were presented in our previous paper [25]. Performing these tests was not possible for the laser-treated samples because too small areas of the films were irradiated and the samples were not suitable for this type of research. 


\section{Results and Discussion}

The properties of new materials, such as temperature, surface chemistry, wettability, hardness, surface roughness, surface reactivity, and surface charge, are some of the essential surface properties of materials. Each of the properties listed above plays a big role in cell adhesion and proliferation. To investigate the surface structure, attenuated total reflectance (ATR) spectroscopy can be used. ATR is a special accessory unit. It can be used with FTIR spectrometers. It enables taking measurements directly over the whole sample surface in the solid state by pressing that sample towards the ATR crystal. In this study, the structure of a hyaluronic acid, collagen/hyaluronic, and collagen/hyaluronic acid with a $30 \%$ addition of chitosan films was characterized by ATR-FTIR spectroscopy. ATR spectra of films based on HA, and mixtures of Coll/HA and Coll/HA/30CTS, have been shown in Figure 2. The obtained spectra are typical for hyaluronic acid, collagen, and chitosan.
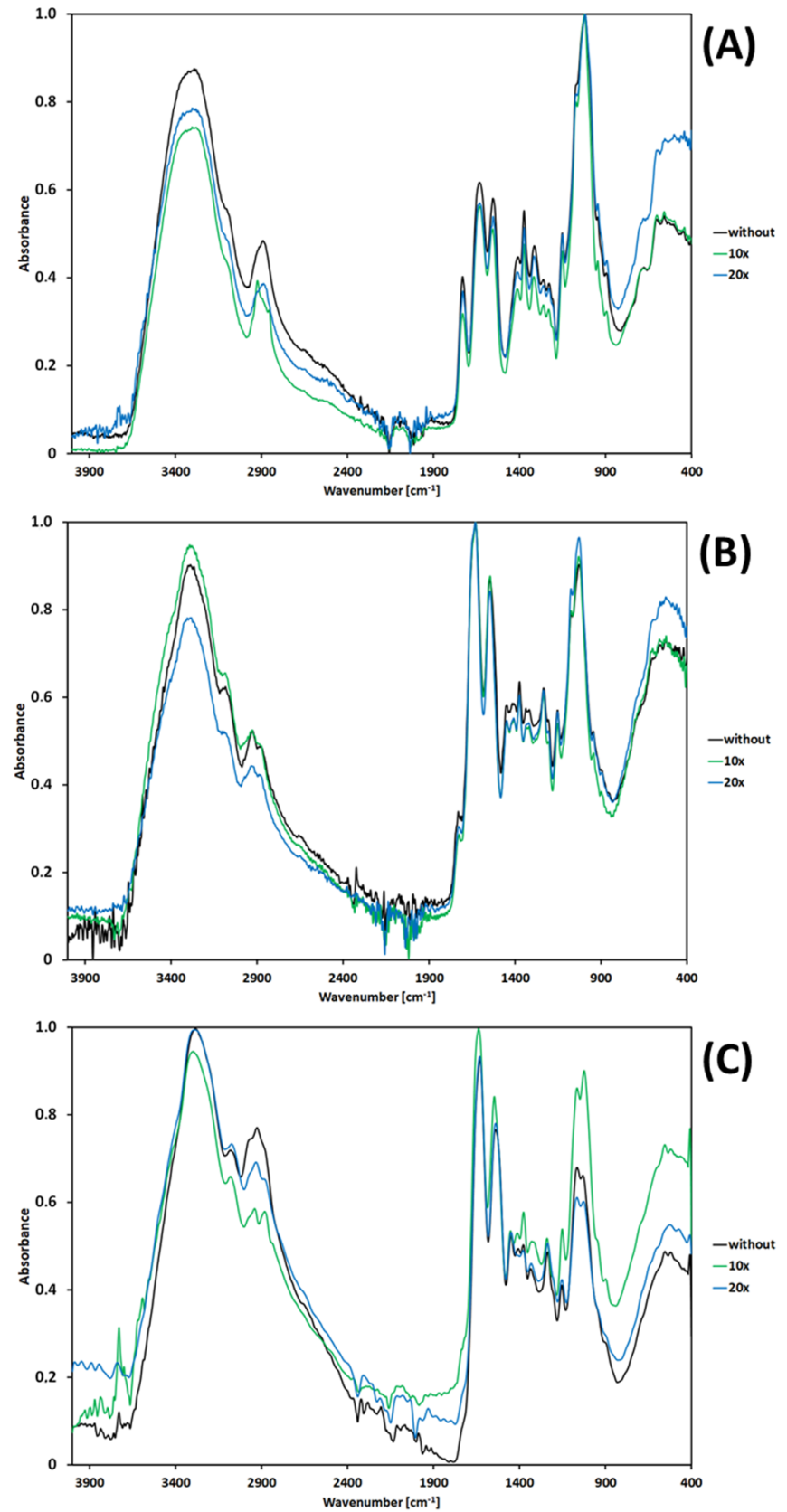

Figure 2. ATR-FTIR spectra of (A) HA, (B) Coll/HA, and (C) Coll/ / HA/30CTS films before and after dose of laser radiation. 
As Figure 2 demonstrates, the strong band at about $3292 \mathrm{~cm}^{-1}$ is rather broad and can be assigned to hydrogen-bonded $\mathrm{OH}$ and $\mathrm{NH}$ stretching vibrations $[27,28]$. The band at around $2889 \mathrm{~cm}^{-1}$ can be observed due to $\mathrm{CH}$ stretching vibrations. The bands at 1632 and $1419 \mathrm{~cm}^{-1}$ can be attributed to the asymmetric $\mathrm{CO}$ and symmetric $\mathrm{CO}$ stretching modes of the planar carboxyl groups in the acid. The absorption bands around 1729, 1547, and $1320 \mathrm{~cm}^{-1}$ are characteristic of the amide I, II, and III bands, respectively [27,28]. Three signals centered near 1147, 1075, and $1020 \mathrm{~cm}^{-1}$ are assigned to the COC (O-bridge), $\mathrm{CO}$ (exocyclic), and $\mathrm{COH}$ groups, respectively. As observed from Figure 2, the overall spectral pattern was not significantly changed after treatment with laser radiation by various numbers of pulses in comparison to untreated specimens. However, the intensity of the strong and wide band at about $3292 \mathrm{~cm}^{-1}$, assigned to the hydrogen-bonded $\mathrm{OH}$, decreased after the laser treatment. This evidences the fact that during the laser treatment the specimens lost water due to the evaporation process. The collagen structure is strongly dependent on water content. Hence, the dynamics of water molecules in collagen play an important role in determining the structural and functional properties of collagen-based materials. The laser treatment led to the destruction of several hydrogen bonds, and the water bonded to collagen was released. Water is also bonded with chitosan and hyaluronic acid via hydrogen bonds; therefore, during the laser treatment the release of water from those biopolymers can also be observed. The release of water from the film based on a single polymer is higher than from the film made of biopolymer blends. There was also evidence of an increase in the concentration of oxygenated surface functional groups with the increase in the pulse frequency of the laser treatment, especially for ternary blends made of collagen, hyaluronic acid, and chitosan. In the blend, the intensity of the band at around 1630-1700 $\mathrm{cm}^{-1}$ is higher than for single biopolymers after laser treatment. This band is related to carbonyl groups in biopolymers. It suggests that oxidation processes occur with higher efficiency on the surface of a ternary blend than on the surface of a film made of a single biopolymer.

Scanning electron microscopy (SEM) was used to study the structure of films made of hyaluronic acid, Coll/HA, and Coll/HA/30CTS before and after laser radiation treatment. SEM images are shown in Figures 3 and 4.

Upon laser treatment, changes in the structure of biopolymeric films are observed. The material expansion into a new foam structure is visible, which is easily observed in the SEM images, especially for the Coll/ / HA/30CTS mixture. For films made of HA, only small alterations were observed, which suggests that those films are more resistant to laser treatment, and surface foaming under experimental conditions is not observed. A more efficient micro-foaming process in films based on ternary blends than those in films made of a single biopolymer is probably due to the higher absorption of laser energy by the blend components. The mechanism of micro-foam formation on some biopolymer films' surfaces was studied in our previous paper, which was regarding laser ablation $[8,9,26]$. Previously, we found that the femtosecond laser irradiation caused an expansion of materials above the surface of collagen films. The received results can be considered in terms of possible ablation mechanisms and compared with the last results obtained previously with nanosecond laser pulses [26].

It was found by Castillejo et al. [27] that ultraviolet laser irradiation with the use of pulses of the duration from the nanosecond to the femtosecond range generated a foam layer on films made of chitosan, starch, and their blends. The example of the possibility of a broader use of laser-induced biopolymer foaming structures in biology is also mentioned in this paper [26]. However, the low-level red laser induced small alterations in fluorescence emission and had a negligible effect on the topography of thin collagen films, as demonstrated by Stylianou et al. [28]. Although irradiation did not affect the nanotopography of collagen, it influenced the cell behavior. Daskalova et al. [29] found that the femtosecond laser treatment of thin films made of collagen, gelatin, and collagen-elastin resulted in the creation of micro/nanopores with different sizes of cavity formations; moreover, the pore sizes could be influenced by tuning the laser parameters. It has been demonstrated 
that any changes in the surface structure after laser treatment depend on laser type, pulse energy, and radiation wavelength. The interaction between a collagen film and UV laser radiation can be complex, and it is a result of the photomechanical regime, with low thermal degradation and combined with photochemical transformations [30].
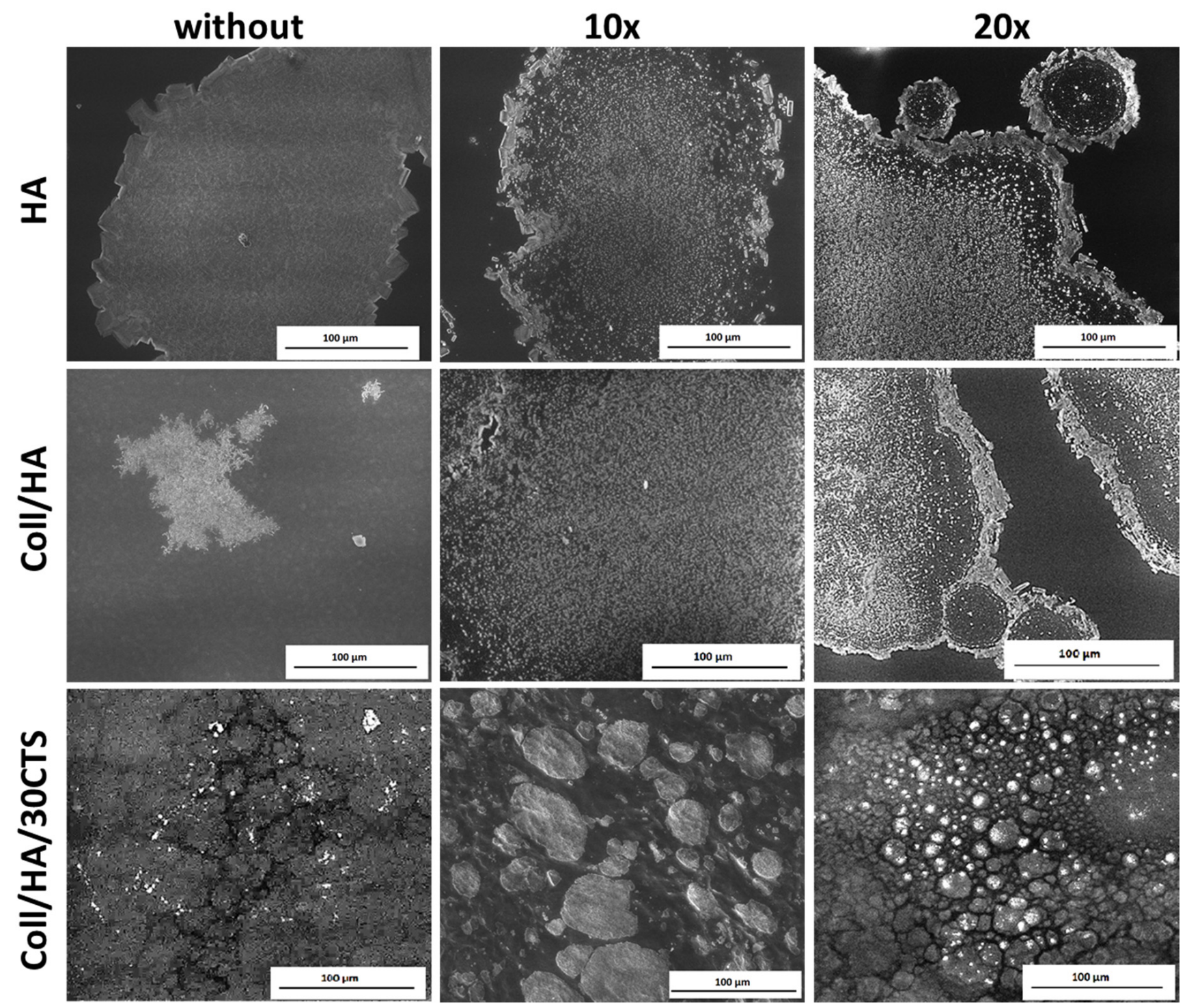

Figure 3. The SEM images of HA, Coll/HA, and Coll//HA/30CTS films before and after treatment of laser radiation (with resolution $100 \mu \mathrm{m}$ ).

In collagen materials, mainly thermal degradation and water evaporation occurs after the IR laser treatment. It was observed by Oh et al. [29] that the thermoelastic effect was generated and the mechanical stress was induced by laser irradiation on collagen with the Nd:YAG laser. The influence of laser radiation on films made of hyaluronic acid has not been widely studied. Preliminary studies on lasers and X-ray irradiation effects on hyaluronic acid dermal fillers have been carried out by Mladenova et al. [30]. It was demonstrated that the FTIR spectra of irradiated samples indicate no substantial changes of the spectral model in the characteristic absorption band regions corresponding to vibrations of the acetamido and carboxylate groups in the pyranose ring. In our study, we treated hyaluronic acid films with the Nd:YAG laser; therefore, results may differ, as hyaluronic acid dermal fillers are usually prepared as hydrogels. 

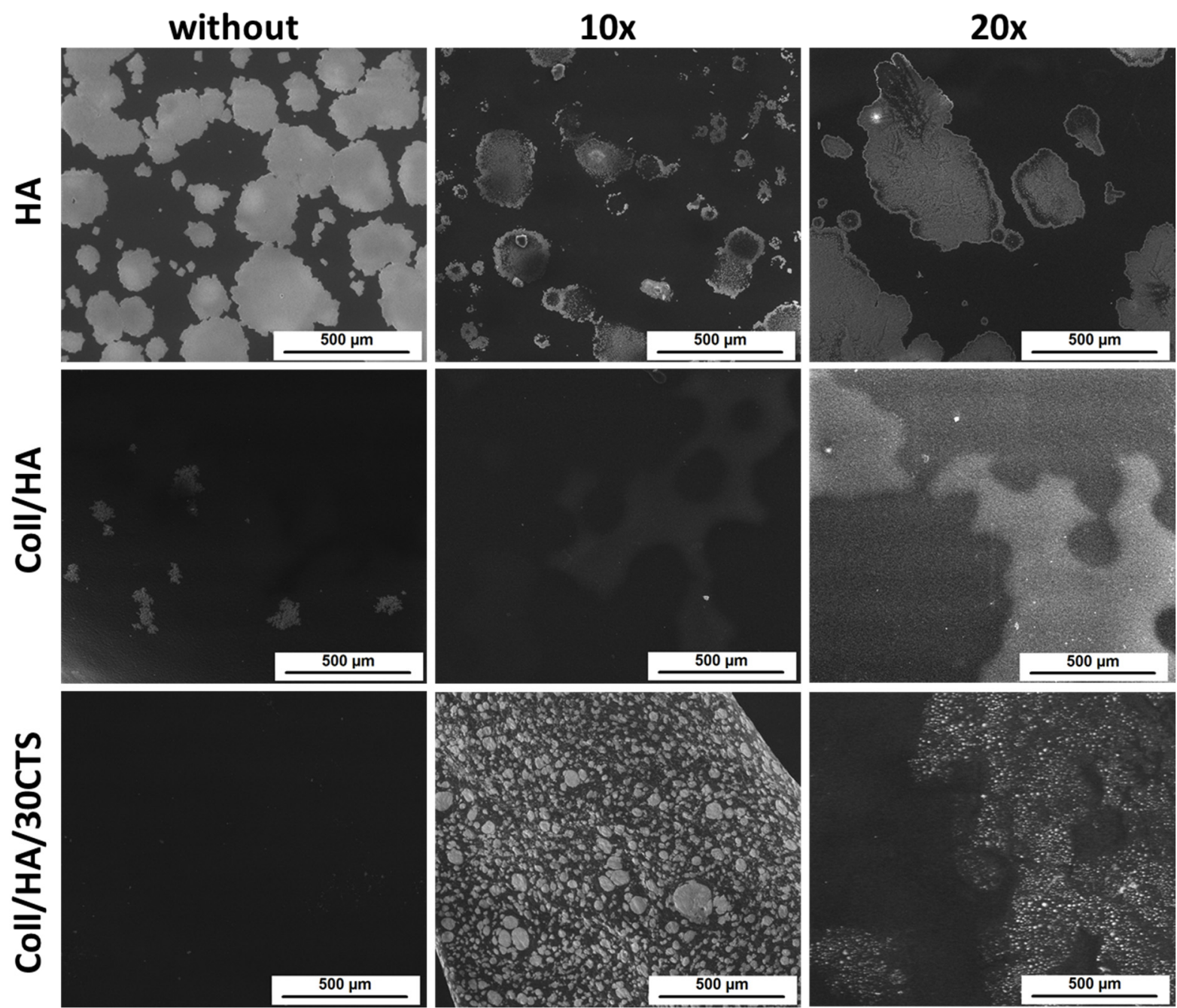

Figure 4. The SEM images of HA, Coll/HA, and Coll/HA/30CTS films before and after treatment of laser radiation (with resolution $500 \mu \mathrm{m}$ ).

The roughness parameters, AFM images, mechanical parameters, and contact angle parameters of native films were presented in our previous paper: Grabska, S.; Sionkowska, A. The Influence of UV-Radiation on Hyaluronic Acid and Its Blends with Addition of Collagen and Chitosan. Int. J. Polym. Anal. Char. 2019, 24, 285-294 [25]. The roughness parameters of laser-treated films are displayed in Table 1.

Table 1. The roughness parameters of laser-treated films based on HA, Coll/HA, and Coll/HA/30CTS.

\begin{tabular}{ccc}
\hline \multirow{2}{*}{ Sample } & \multicolumn{2}{c}{ Laser-Treated Films $(\mathbf{2 0} \times \mathbf{)}$} \\
\cline { 2 - 3 } & $\mathbf{R q}[\mathbf{n m}]$ & $\mathbf{R a}[\mathbf{n m}]$ \\
\hline HA & 19.40 & 16.70 \\
Coll/HA & 112.50 & 99.30 \\
Coll/HA/30CTS & 9.06 & 7.99 \\
\hline
\end{tabular}

Rq-mean square deviation of surface roughness; Ra-mean arithmetic deviation of the profile from the mean line.

Based on our previous study, it can be observed that AFM images display differences in the surface of films based on hyaluronic acid and its mixture with collagen and chitosan [25]. The AFM images demonstrate that the films based on hyaluronic acid and Coll/HA/30CTS are characterized by a smoother surface than the Coll/HA film [25]. The surface of the three-component film was similar to the hyaluronic acid film surface and these results are related to the interactions between hyaluronic acid, collagen, and chitosan [25]. 
Comparing the roughness parameters values for the films before and after the laser treatment, significant changes can be observed. The surface of the films after laser treatment was characterized by higher parameters of $\mathrm{Rq}$ (mean square deviation of surface roughness) and $\mathrm{Ra}$ (mean arithmetic deviation of the profile from the mean line). These observations are consistent with the SEM images (Figures 3 and 4).

Otherwise, in general, the roughness of the surface increases after the treatment of polymer films with lasers [6,31,32]. Daskalova et al. [32] report that from the AFM results pure chitosan film treated with laser, and the roughness parameter increases when the intensity of the laser increases. According to Volova et al. [31], pristine films based on poly-3-hydroxybutyrate demonstrated the lowest values of roughness parameters, such as: arithmetic mean surface roughness, root mean square roughness, or peak-to-valley height, relative to materials treated with the $\mathrm{CO}_{2}$ laser LaserPro Explorer II. On the other hand, Michaljaničová et al. [6] compared the effect of the $\mathrm{KrF}$ and ArF lasers on the surface of poly(lactic acid) and polyhydroxybutyrate, and they reported an increase in surface roughness for polyhydroxybutyrate, regardless of the laser used. An increase in surface roughness for the poly(lactic acid) with the ArF laser treatment and a decrease for the $\mathrm{KrF}$ laser treatment was observed.

Overall, the roughness of film surface is a consequence of the laser treating and additional side effects, such as pores and foam formation, cracks, and damages [6,31,32].

Our previous paper, where the same materials were irradiated with UV light, demonstrates the parameters of the mechanical properties and the contact angle for the tested materials prior to laser treatment.

The films that are the subject of this work, unfortunately, after laser treatment, were not suitable for investigating the mechanical properties and the contact angle measurements. Therefore, we decided to quote only the previous results [25]. We dare to say that when the films are treated with laser, the mechanical properties of the materials becomes a little better, which was observed for the laser-deposited poly(methyl methacrylate) films [33], while the contact angle for the polar liquid (glycerin) of the films decreased, which was the case for the PLLA-plasma-treated materials [34].

\section{Conclusions}

The treatment of biopolymeric films made of hyaluronic acid, and those made of the blend of collagen and hyaluronic acid as well as the ternary Coll/HA/chitosan blend with pulse neodymium laser radiation, led to the alterations of the surface properties. After the laser treatment, oxidation processes occurred on the biopolymeric films, and the micro-foam formation was observed. Micro-foaming occurred with higher efficiency in the films based on ternary blends than in those made of a single biopolymer. It can be assumed that laser treatment can be used to tailor the material properties based on the ternary blends of biopolymers for potential biomedical applications.

Author Contributions: Conceptualization, S.G.-Z. and A.S.; methodology, S.G.-Z.; software, S.G.-Z. and A.S.; validation, S.G.-Z. and A.S.; formal analysis, S.G.-Z.; investigation, S.G.-Z.; resources, A.S.; data curation, S.G.-Z.; writing—original draft preparation, S.G.-Z.; writing—review and editing, S.G.Z. and A.S.; visualization, S.G.-Z.; supervision, A.S.; project administration, A.S.; funding acquisition, A.S. All authors have read and agreed to the published version of the manuscript.

Funding: This work was supported by the Polish National Science Centre (NCN) under grant 2013/11/B/ST8/04444.

Institutional Review Board Statement: Not applicable.

Informed Consent Statement: Not applicable.

Data Availability Statement: The data presented in this study are available on request from the corresponding author.

Acknowledgments: Grateful acknowledgements to Agata Kołodziejczak-Czubachowska for the obtaining of biopolymeric films and help with the sample irradiation. 
Conflicts of Interest: The authors declare no conflict of interest.

\section{References}

1. Jaganathan, S.K.; Balaji, A.; Vellayappan, M.V.; Subramanian, A.P.; John, A.A.; Asokan, M.K.; Supriyanto, E. Review: RadiationInduced Surface Modification of Polymers for Biomaterial Application. J. Mater. Sci. 2015, 50, 2007-2018. [CrossRef]

2. Peethan, A.; Unnikrishnan, V.K.; Chidangil, S.; George, S.D. Laser-Assisted Tailoring of Surface Wettability-Fundamentals and Applications: A Critical Review. Rev. Adhes. Adhes. 2019, 7, 331-365. [CrossRef]

3. Krishnan, A.; Fang, F. Review on Mechanism and Process of Surface Polishing Using Lasers. Front. Mech. Eng. 2019, 14, 299-319. [CrossRef]

4. Kusinski, J.; Kac, S.; Kopia, A.; Radziszewska, A.; Rozmus-Górnikowska, M.; Major, B.; Major, L.; Marczak, J.; Lisiecki, A. Laser Modification of the Materials Surface Layer-a Review Paper. Bull. Polish Acad. Sci. Tech. Sci. 2012, 60, 711-728. [CrossRef]

5. Kurella, A.; Dahotre, N.B. Review Paper: Surface Modification for Bioimplants: The Role of Laser Surface Engineering. J. Biomater. Appl. 2005, 20, 5-50. [CrossRef] [PubMed]

6. Michaljaničová, I.; Slepička, P.; Heitz, J.; Barb, R.A.; Sajdl, P.; Švorčík, V. Comparison of KrF and ArF Excimer Laser Treatment of Biopolymer Surface. Appl. Surf. Sci. 2015, 339, 144-150. [CrossRef]

7. Michaljanicova, I.; Slepicka, P.; Rimpelova, S.; Sajdl, P.; Svorcík, V. Surface Properties of Laser-Treated Biopolymer. Mater. Technol. 2016, 3, 331-335. [CrossRef]

8. Lazare, S.; Sionkowska, A.; Zaborowicz, M.; Planecka, A.; Lopez, J.; Dijoux, M.; Louména, C.; Hernandez, M.C. Bombyx Mori Silk Protein Films Microprocessing with a Nanosecond Ultraviolet Laser and a Femtosecond Laser Workstation: Theory and Experiments. Appl. Phys. A-Mater. 2012, 106, 67-77. [CrossRef]

9. Lazare, S.; Tokarev, V.; Sionkowska, A.; Wiśniewski, M. Surface Foaming of Collagen, Chitosan and Other Biopolymer Films by KrF Excimer Laser Ablation in the Photomechanical Regime. Appl. Phys. A-Mater. 2005, 81, 465-470. [CrossRef]

10. Sionkowska, A. Current Research on the Blends of Natural and Synthetic Polymers as New Biomaterials: Review. Prog. Polym. Sci. 2011, 36, 1254-1276. [CrossRef]

11. Hemshekhar, M.; Thushara, R.M.; Chandranayaka, S.; Sherman, L.S.; Kemparaju, K.; Girish, K.S. Emerging Roles of Hyaluronic Acid Bioscaffolds in Tissue Engineering and Regenerative Medicine. Int. J. Biol. Macromol. 2016, 86, 917-928. [CrossRef]

12. Zhai, P.; Peng, X.; Li, B.; Liu, Y.; Sun, H.; Li, X. The Application of Hyaluronic Acid in Bone Regeneration. Int. J. Biol. Macromol. 2020, 151, 1224-1239. [CrossRef] [PubMed]

13. Necas, J.; Bartosikova, L.; Brauner, P.; Kolar, J. Hyaluronic Acid (Hyaluronan): A Review. Vet. Med. 2008, 53, 397-411. [CrossRef]

14. Maharjan, A.S.; Pilling, D.; Gomer, R.H. High and Low Molecular Weight Hyaluronic Acid Differentially Regulate Human Fibrocyte Differentiation. PLoS ONE 2011, 6, e26078. [CrossRef] [PubMed]

15. Choi, S.Y.; Kwon, H.J.; Ahn, G.R.; Ko, E.J.; Yoo, K.H.; Kim, B.J.; Lee, C.; Kim, D. Hyaluronic Acid Microneedle Patch for the Improvement of Crow's Feet Wrinkles. Dermatol. Ther. 2017, 30, e12546. [CrossRef] [PubMed]

16. John, H.E.; Price, R.D. Perspectives in the Selection of Hyaluronic Acid Fillers for Facial Wrinkles and Aging Skin. Patient Prefer. Adher. 2009, 3, 225.

17. Pavicic, T.; Gauglitz, G.G.; Lersch, P.; Schwach-Abdellaoui, K.; Malle, B.; Korting, H.C.; Farwick, M. Efficacy of Cream-Based Novel Formulations of Hyaluronic Acid of Different Molecular Weights in Anti-Wrinkle Treatment. J. Drugs Dermatol. 2011, 10, 990-1000.

18. Ferreira, A.M.; Gentile, P.; Chiono, V.; Ciardelli, G. Collagen for Bone Tissue Regeneration. Acta Biomater. 2012, 8, 3191-3200. [CrossRef]

19. Rinaudo, M. Main Properties and Current Applications of Some Polysaccharides as Biomaterials. Polym. Inter. 2008, 57, 397-430. [CrossRef]

20. Kumar, M.N.V.R.; Muzzarelli, R.A.A.; Muzzarelli, C.; Sashiwa, H.; Domb, A.J. Chitosan Chemistry and Pharmaceutical Perspectives. Chem. Rev. 2004, 104, 6017-6084. [CrossRef] [PubMed]

21. Jayakumar, R.; Prabaharan, M.; Nair, S.V.; Tokura, S.; Tamura, H.; Selvamurugan, N. Novel Carboxymethyl Derivatives of Chitin and Chitosan Materials and Their Biomedical Applications. Prog. Mater. Sci. 2010, 7, 675-709. [CrossRef]

22. Lewandowska, K.; Sionkowska, A.; Grabska, S.; Kaczmarek, B.; Michalska, M. The Miscibility of Collagen/Hyaluronic Acid/Chitosan Blends Investigated in Dilute Solutions and Solids. J. Mol. Liq. 2016, 220, 726-730. [CrossRef]

23. Lewandowska, K.; Sionkowska, A.; Grabska, S.; Kaczmarek, B. Surface and Thermal Properties of Collagen/Hyaluronic Acid Blends Containing Chitosan. Int. J. Biol. Macromol. 2016, 92, 371-376. [CrossRef] [PubMed]

24. Sionkowska, A.; Kaczmarek, B. Preparation and Characterization of Composites Based on the Blends of Collagen, Chitosan and Hyaluronic Acid with Nano-Hydroxyapatite. Int. J. Biol. Macromol. 2017, 102, 658-666. [CrossRef]

25. Grabska, S.; Sionkowska, A. The Influence of UV-Radiation on Hyaluronic Acid and Its Blends with Addition of Collagen and Chitosan. Int. J. Polym. Anal. Char. 2019, 24, 285-294. [CrossRef]

26. Sionkowska, A.; Lewandowska, K.; Grabska, S.; Kaczmarek, B.; Michalska, M. Physico-Chemical Properties of Three-Component Mixtures Based on Chitosan, Hyaluronic Acid and Collagen. Mol. Cryst. Liq. Cryst. 2016, 640, 21-29. [CrossRef]

27. Kim, J.K.; Srinivasan, P.; Kim, J.H.; Choi, J.-I.; Park, H.J.; Byun, M.W.; Lee, J.W. Structural and Antioxidant Properties of Gamma Irradiated Hyaluronic Acid. Food Chem. 2008, 109, 763-770. [CrossRef] [PubMed] 
28. Wu, Y. Preparation of Low-Molecular-Weight Hyaluronic Acid by Ozone Treatment. Carbohyd. Polym. 2012, 89, 709-712. [CrossRef]

29. Oh, H.B.; Kim, J.S.; Jung, G.I.; Baek, J.Y.; Kim, J.; Jun, J.H. Change of Induced Stress Wave on Collagen Tissue for Biostimulation by Frequency-Doubled Nd:YAG Laser. J. Mech. Med. Biol. 2018, 18, 1840003. [CrossRef]

30. Mladenova, R.; Karakirova, Y.; Shopska, M.; Sabatinov, O.; Gyurova, M. Preliminary Study on Lasers and X-Ray Irradiation Effects on Hyaluronic Acid Dermal Fillers. Comptes Rendus L'academie Bulg. Sci. 2018, 50, 1451-1457.

31. Volova, T.G.; Golubev, A.I.; Nemtsev, I.V.; Lukyanenko, A.V.; Dudaev, A.E.; Shishatskaya, E.I. Laser Processing of Polymer Films Fabricated from PHAs Differing in Their Monomer Composition. Polymers 2021, 13, 1553. [CrossRef] [PubMed]

32. Daskalova, A.; Bliznakova, I.; Angelova, L.; Trifonov, A.; Declercq, H.; Buchvarov, I. Femtosecond Laser Fabrication of Engineered Functional Surfaces Based on Biodegradable Polymer and Biopolymer/Ceramic Composite Thin Films. Polymers 2019, 11, 378. [CrossRef] [PubMed]

33. Süske, E.; Scharf, T.; Krebs, H.U.; Panchenko, E.; Junkers, T.; Egorov, M.; Buback, M.; Kijewski, H. Tuning of Cross-Linking and Mechanical Properties of Laser-Deposited Poly (Methyl Methacrylate) Films. J. Appl. Phys. 2005, 97, 063501. [CrossRef]

34. Slepička, P.; Michaljaničová, I.; Švorčík, V. Controlled Biopolymer Roughness Induced by Plasma and Excimer Laser Treatment. Express Polym. Lett. 2013, 7, 950-959. [CrossRef] 